\title{
Gauging the Reception of Choice Reviews through Online Union Catalog Holdings
}

\author{
John C. Calhoun
}

\begin{abstract}
The reviews in Choice are known to influence book selection, particularly for academic library collections. An investigation was made of how many books that were reviewed over a seven-year period in Choice Reviews (the $C D-R O M$ version of Choice) were subsequently received or purchased at Cain Library of California State University Dominguez Hills (CSUDH), as well as by a large number of other libraries across the country. All of the books mentioned in Choice Reviews were purchased by one or more libraries, while the majority of books were purchased by several hundred libraries. These findings were further tested to determine the extent to which they could be incorporated into an academic approval program. Two notificationslip approval plans were created for new titles from the presses and publishers of the best-received books. Notification-slip titles were searched shortly after they appeared or were profiled by the vendors, and a correlation was found between the later review holdings and these early approval holdings.
\end{abstract}

$\checkmark$ auging the reception of a particular title from Choice Reviews (the CD-ROM version of Choice) in a single library requires only finding a bibliographic record for the title in the local catalog. If the record is there, the title was well received. The reception of a particular title, defined in this case as the purchase and inclusion of a title in a library collection, is usually the result of an individual's intellectual interest moderated to some extent by the institution's financial constraints that together suggest the item would be a worthwhile addition to the collection. Typically this is because a member of the teaching faculty has suggested a firm order to an acquisitions librarian, or a subject bibliog- rapher has selected a title from an approval program previously set up with an academic vendor. Over the course of time then, using a union catalog, we can judge the reception, not only of particular titles in particular library collections, but of whole groups of titles in a large number of academic library collections - either by discipline or across disciplines-on the basis of characteristics such as the titles having been included in Choice Reviews.

For single disciplines, we can search records in the local catalog by subject. We also can search across disciplines in the local catalog by searching multiple subject terms that would transcend a single main class. Alternatively, we can search across

John C. Calhoun (jccalhoun@dhvx20.csudh.edu)is Collection Development Librarian, California State University Dominguez Hills, Carson, California. Manuscript received for publication July 21, 1997; accepted for publication September 23, 1997. 
disciplines using additional data elements, such as publisher, when there is a well-defined set of these additional data elements available.

Local catalogs can handle the first of these reception studies easily because access by subject has been built into the file structure. Some local catalogs would accommodate the second kind of reception study (across disciplines) because the searching can be repetitive in nature, using several subject terms, or because additional access by other data elements, such as publisher, has been included as a special feature of the indexing. Searching by additional data elements such as publisher is a special feature in the OCLC Online Computer Library Center, Inc. Online Union Catalog (OLUC) as well; and searching the OLUC also provides holdings information that indicates whether the title has been purchased and included in the collections of a number of libraries. The OLUC, however, does not indicate whether a title was reviewed in Choice or any other reviewing service. Determining that information required using Choice Reviews itself, and it was that circumstance that suggested the rationale of creating a single database with both the requisite data elements and access capabilities to make an efficient investigation of the extent to which books reviewed by Choice were purchased by libraries across the country.

There were several aspects to this study. The first was to create this database, which was done by superimposing the holdings data of machine-readable bibliographic records from the OLUC onto the corresponding records from Choice Reviews. The second was to use this database to gauge the reception of the books reviewed by Choice both in the local academic library collection-the Cain Library at California State University, Dominguez Hills (CSUDH) - as well as in a large number of other, presumably academic, library collections across the country as reflected by OLUC holdings. The third was to collate the information from the reception of the books reviewed by Choice and acknowledged in the OLUC holdings to design an academic approval program that would accurately forecast what the best-received materials were most likely to be.

\section{LITERATURE REVIEW}

Two articles were the conceptual antecedents of the present study. In the first, Balay (1988) described how the machinereadable bibliographic records for Choice Reviews were created in September 1988 and hypothesized future research for these records, such as discipline-oriented or cross-disciplinary searching. In the second, Serebnick (1992) analyzed the holdings of OCLC member libraries for a diverse group of small press titles published in 1986 to find a relation between library holdings and book reviews from core journals such as Choice and other review journals, publisher's catalogs, and vendor information. In the current study, I replicated the method used by Serebnick but restricted the domain of review journals searched to a single journal, Choice. The selection of Choice reflects the high value placed on its reviews as seen in the heavy use of the reviews in both the selection and collection evaluation processes.

Most depictions of Choice in the literature (e.g., MacLam 1992, or Graf 1995) have been supportive of the work of its highly qualified reviewers. In addition, the editors weed out about $70 \%$ of what is submitted for review, and at the end of each year produce a list of about $10 \%$ of what has been reviewed for the annual Outstanding Academic Books (OAB) list. In contrast, Leavy (1992) has suggested that this $\mathrm{OAB}$ list has absolutely no validity.

Other critics have not been willing to draw such an extreme conclusion, although they have suggested-through content analysis (Carlo and Natowitz 1995) or some form of quantitative study (Greene and Spornick 1995) - that the vast majority of the reviews that have appeared in major review sources (including Choice) have been favorable, perhaps too favorable. MacLam (1992) attributes this to an editorial process that weeds out inappropriate material and recognizably bad books, which is a serv- 
ice provided by any good review journal.

On another dimension, the review coverage in Choice proved to be an accurate reflection, over a three-year period, of the subject proportions of the market identified in Books Published Annually from Publishers Weekly (Sabosik 1992). And the difference in use between titles reviewed by Choice from university presses (5.091) and titles reviewed by Choice from commercial publishers (6.404), in a representative academic setting, proved to be less than had been anticipated (Saunders 1996).

The OAB list is an aspect of Choice Reviews that has attracted a good deal of attention. Marquet and Diambra (1990) suggested that the OAB lists could be used to document a decline in both the quantity and quality of holdings from a midsized academic library. In a second study, Calhoun, Bracken, and Firestein (1990) suggested that the $\mathrm{OAB}$ presses and publishers would form an 80/20 core that could be used to model an academic approval program. Goedeken (1993) showed that, unlike the proportion found for Choice in general, the proportion of university presses to commercial publishers has increased significantly among $\mathrm{OAB}$ lists in the last ten years. Metz and Stemmer (1996) found, not surprisingly, that the reputation of these $\mathrm{OAB}$ presses and publishers is an important influence on macro-level decision making of collection development officers in the design of approval plans.

In addition to uses of the $\mathrm{OAB}$ lists as postselection assessment tools, Stebelman (1996) suggested that frequently cited publishers from Choice Reviews, particularly when arranged by Library of Congress main classes, are the best source for an academic library to use in maintaining its acquisitions program. Erickson (1992) recommended cooperative collection development based on book reviews from Choice as a way to stretch budgets and provide more titles without compromising the quality of individual collections.

Just as Choice Reviews-on-Cards might be used for cross-disciplinary selection from a single issue in such a cooperative project, so too might vendor referral slips be used for discipline-oriented selection over a period of time equivalent to several issues in a retrospective project, affording bibliographers a perspective of what actually had been published. This last was the suggestion of Childress and Gibbs (1989). From these two instances, it would seem that cross-disciplinary selection from a single issue or disciplineoriented selection from several issues might be worthwhile characteristics to include in any large-scale study of the reception of Choice Reviews.

Finally, the utility of a recommended core list such as Books for College Librar$i e s, 3 \mathrm{~d}$ ed. might be limited by availability of the books (Budd 1991). Therefore, including the length of time after the appearance of each $\mathrm{OAB}$ list during which titles still were being actively purchased is an important piece of information to take full advantage of what the reception study tells us and to make that a part of an academic approval program.

\section{METHOD}

We started with the creation of a relational database of machine-readable bibliographic records developed from Choice Reviews and the OLUC. To increase the accuracy of the file, the holdings were normalized by date of issue and the subject categories were normalized by main class.

When the normalized database was sorted by main class, the second step of the study-an analysis by disciplinemade it possible to gauge the reception of a particular group of titles reviewed in Choice, specifically the $\mathrm{OAB}$ items in a large number of academic library collections. It was also possible to gauge a more general group of titles reviewed in Choice (those selected by CSUDH bibliographers) in a single academic library collection.

When the normalized database was sorted by publisher, the third step of the study - an analysis of the file across disciplines-made it possible to gauge the reception of university-press and commercial-publisher titles in a large number of academic library collections. Those 


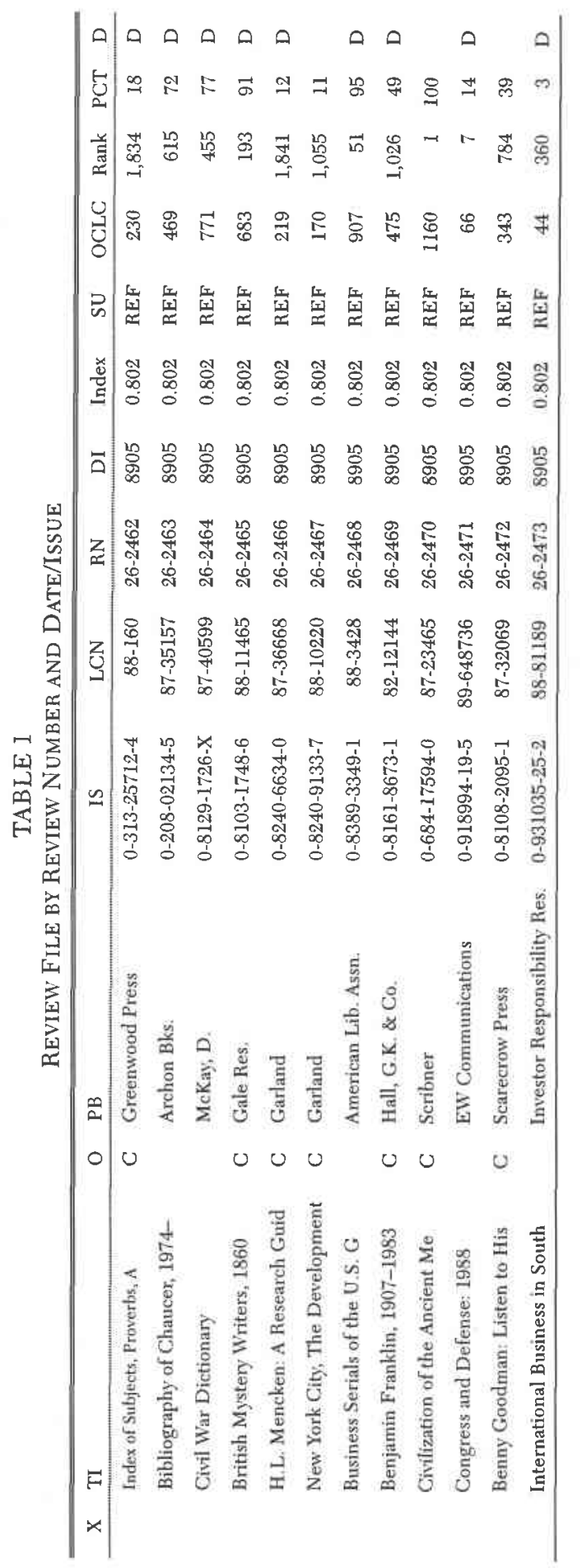


core presses and core publishers could then be used as the basis for two notification-slip approval plans in a single academic library collection.

In the final step of the study, the approval titles were searched in the OLUC shortly after they were profiled by the vendors; and following the first year of the program, the early searches of the approval titles were correlated with the later searches of the review titles. The definition of the $70 / 30$ approval core and the $60 / 40$ review core (the timely purchase of the most likely candidates to become $\mathrm{OAB}$ and later to be included in the fourth edition of Books for College Libraries) were used as comparison.

\section{Constructing the Database from Cholce Reviews AND THE OLUC}

Table 1 shows a display of bibliographic records from the top of a file that I was able to obtain from Choice Reviews in January 1995 using a locally developed program. These records existed because of the decision to put the reviews beginning with the September 1988 issue of Choice into machine-readable form (Balay 1988). In the display, the bibliographic records appear as rows and the fields of the bibliographic records appear as columns. Most of the fields are identified with two- or three-letter mnemonics that are recognizable from Choice $\mathrm{Re}$ views (TItle, PuBlisher, International Standard book number, Library of Congress control Number, Review Number, Date/Issue, and SUbject). From the sequence of review numbers, it will be clear that I intended to search all reviewed titles to ensure finding the OLUC holdings for a general group of large press titles published over several years but reviewed in a single core journal-in contrast to Serebnick (1992), who used a sophisticated sampling technique to ensure finding OLUC holdings for a select group of small press titles published in a single year but reviewed in several core journals.

Table 2 shows the initial intent of the project, which was to sort the file by the three-letter mnemonic for subject category (in this case, African Studies, or
AFR) and then to subarrange it in descending order by the OLUC holdings. Once the titles had been sorted and subarranged in this fashion, each could be assigned a rank (to facilitate discipline-oriented searching) and a percentile expression of rank (to facilitate crossdisciplinary searching) with short programs, to indicate how well each had been received among its peers from this subject category in the OLUC. Before this could be realized, however, some means had to be found to standardize the age of the records in the file. This was done because some reviews were issued in January 1989 (DI=8905), and thus would have had as much as eight years to accumulate holdings; while others were issued in January 1995 (DI=9505), and thus would have had as little as two years to accumulate holdings.

Figure 1 might help to make this technical problem clear. Our first searching project in the OLUC, covering titles from the years 1989 to 1994 , occurred in February and March 1995 (equivalent to 9506 and 9507 on the bar graph, because each calendar year begins with issue 5 of Choice Reviews). When we compared the results of this large-scale searching project year by year, we elected to discard the 1994 data because first of all the data appeared to shelve off abruptly, and second, the OAB list for 1994 had just appeared, and we thought that might result in additional purchases that would not be reflected in the data. The results for 1989 through 1993 stepped up at a very modest rate of about $5 \%$ a year, and they seemed, in contrast to more recent purchases, almost plateau-like.

Our second searching project in the OLUC, looking again at titles from the year 1994, occurred in February 1996 (equivalent to 9606 on the graph). When the results of this second project were compared to the data for 1993 from the first project, we were pleased to see that the average holdings for 1993 and 1994 were almost identical. The appearance of the succeeding year's OAB list appeared to have a stabilizing effect on the penultimate year's holdings-in effect, closing the door on active purchases from the 


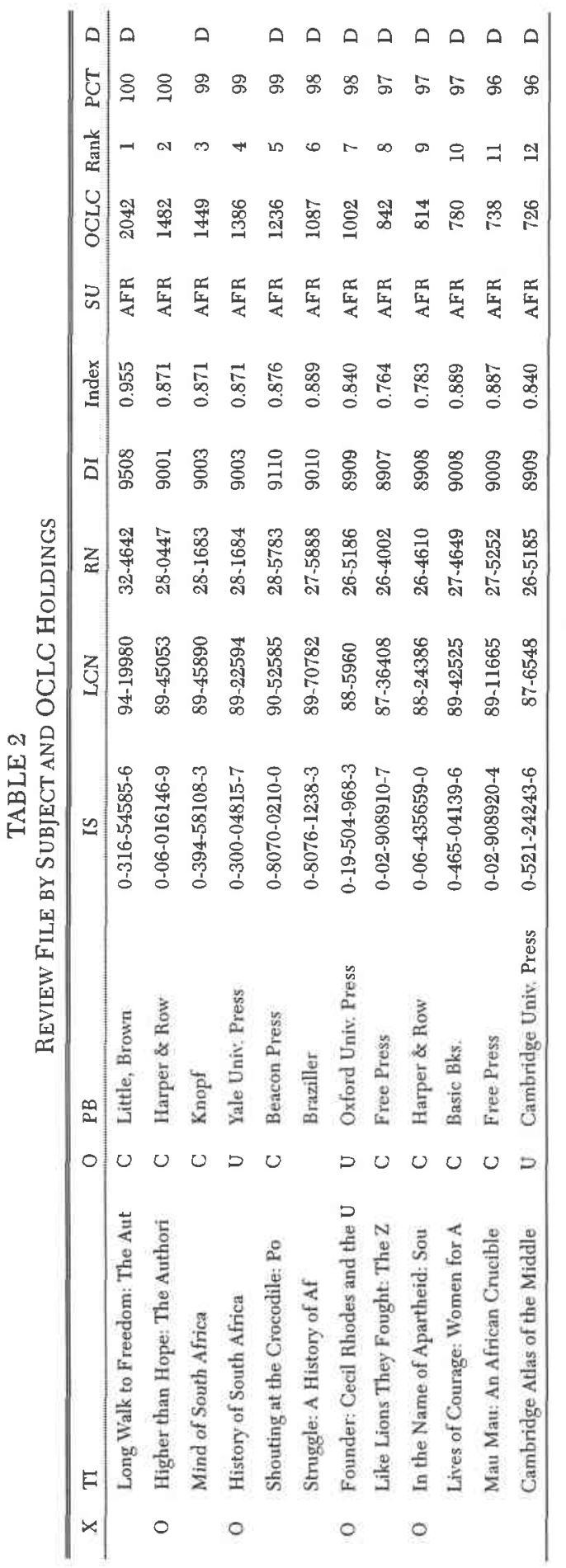




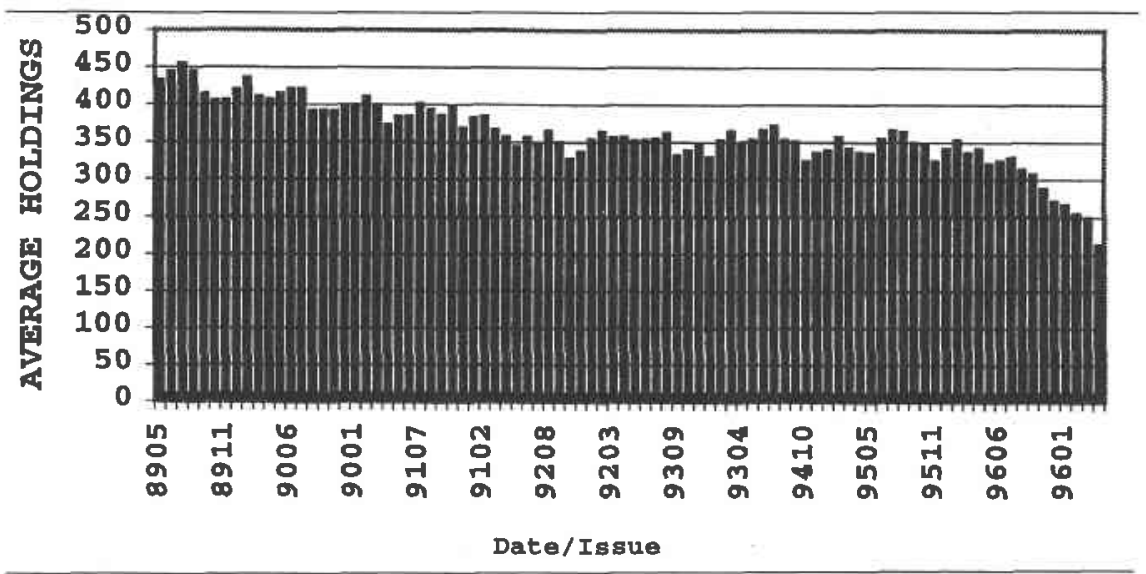

Figure 1. Average Holdings by Date/Issue.

previous year's OAB list. Following this, I was able to obtain another two-year file of machine-readable bibliographic records from Choice Reviews.

Our third searching project, for titles from the year 1995, occurred in February 1997. When we compared the results of this third project to the results for 1993 from the first project and to the results for 1994 from the second project, we were pleased to see that the average holdings for all three years were almost identical. This seemed to confirm that the appearance of the succeeding year's OAB list had a stabilizing effect on the penultimate year's holdings. As an addendum to this third project, we also searched the 1996 titles in April 1997, and the reader can see the effect of this early searching (which was very similar to our initial results for 1994 titles from the first project) in the shelving off of the average holdings in the 1996 dates of issue at the far right of the figure.

After some consideration, we decided to take the 1993 results from the first project, the 1994 results from the second project, and the 1995 results from the third project as our norm. We indexed the average holdings for each date of issue in the file to this value. This process of normalizing the holdings ensured that the titles from each volume and number would be weighted equally and that the dates of issue would be consistent throughout the file. At the same time, because our approval vendors used $\mathrm{Li}$ brary of Congress (LC) main class to sort and arrange their notification slips (rather than the three-letter mnemonics for Choice subject categories that we had devised), we also decided to use Main Class as our norm in place of Subject Category.

\section{Finst Use of the Database: Discipline-Oriented (Main Class) SEARCHING AND ANALYSIS}

Table 3 shows a sample of the results of this normalization process: 44,950 titles with dates of issue from 1989 through 1995 were sorted in a single file by LC main class (in this case, for General Works: Collections, Encyclopedias, and Dictionaries; $\mathrm{AC}, \mathrm{AE}$, and $\mathrm{AG}$ ) and subarranged in descending order by OLUC normalized holdings. Once the titles had been sorted and subarranged, each could be assigned a rank and a percentile expression of rank with short programs (under RANK and PCT, between the OLUC holdings and the Dominguez Hills holdings) to indicate how well each had been received among its peers from these main classes in the OLUC. Once our method was developed to the point that it permitted us to use a consistent file of this size, we could begin to answer some questions about the reception of titles from Choice Reviews on an empirical, rather than a 


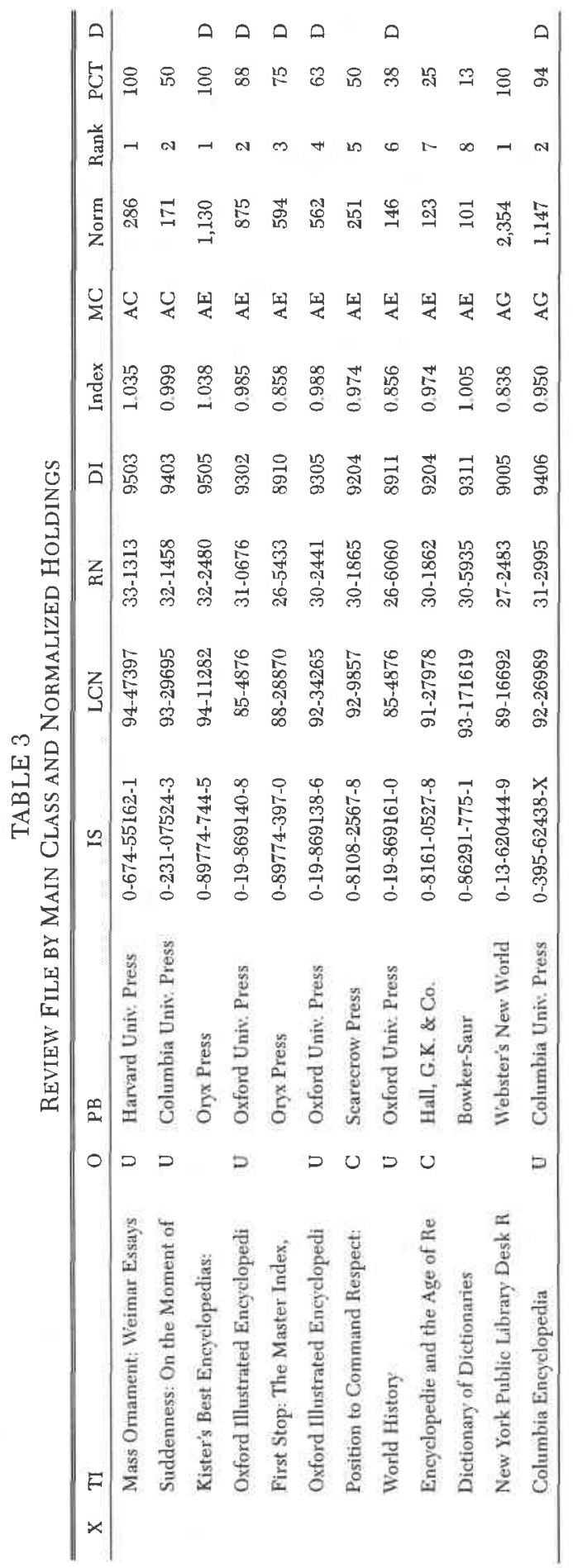


theoretical, basis. We included codes for $\mathrm{OAB}$ titles as well as CSUDH titles in the file (O at the far left, and D at the far right), for example. So all that was required to create discipline-oriented subsets of these from the seven-year review file was a feature of the dBase software called SET FILTER.

Table 4 shows a subset of $\mathrm{OAB}$ titles created by setting the filter to $\mathrm{X}=$ "OO." Because their rank and the percentile expression of that rank (which is independent of a particular main class) had already been assigned in the seven-year review file, very little extra was required to find the mean (71) or the median (76) for this subset. There may have been nothing, a priori, among the 1,335 graded book review citations attached to the 460 $\mathrm{OAB}$ titles in the General Periodicals Index to support Leavy's (1992) findings of the superiority of Choice's OAB. However, there certainly seems to be something, a posteriori, among the 2,229,926 holdings attached to the 4,209 OAB titles in the OLUC to suggest taking another look.

More than once the editors at Choice have pointed out the primary role the reviewers (typically undergraduate teaching faculty with expertise in the subject) play in the review process (Graf 1995; MacLam 1992). The reviewers must say, in their own 200 words, that the title is outstanding before the editors can select it as part of their annual $\mathrm{OAB}$ list. It might be true, as some critics have said, that most book reviews are favorable (e.g., Carlo and Natowitz 1995; Greene and Spornick 1995). But a very large number of bibliographers have responded to the $\mathrm{OAB}$ lists in a way that suggests the reviews represented by the lists are much more favorable than most reviews, and the conclusion seems inescapable: an overwhelming majority of the librarians who buy academic books view these titles as outstanding.

Table 5 shows a subset of CSUDH titles created by setting the filter to $\mathrm{D}=$ " $\mathrm{D}$." Again, because their rank and the percentile expression of that rank (which is independent of a particular main class) had already been assigned in the seven- year review file, very little extra was required to find the mean (63) and median (67) for this subset. That CSUDH has been buying some of the best-received, or weightiest, titles from Choice Reviews for the past seven years is good to know because we were only able to buy 15,285 of the 44,950 titles reviewed (34\%). We have a Western Association of Schools and Colleges (WASC) review coming up in which we will almost certainly be asked how well we have done with our declining funds. Our very modest share of titles from Choice Reviews will be significantly enhanced by the $44 \%$ share of normalized holdings or purchases attached to them in the OLUC. A more serious difficulty, however, may be the unequal distribution of that $34 \%$ or $44 \%$ share of the total - a fact that another bar graph will help to make clear.

Figure 2 shows the local holdings from CSUDH as a percentage of reviewed titles from Choice in the most frequently seen LC main classes. The editor and publisher have established already that the review coverage in Choice is an accurate reflection of the subject proportions of books published (Sabosik 1992). Within the context of what has been published, our overall performance for 1989 through 1995 was that we were able to buy one title for every three reviews. We will argue that, because we have been careful to buy the better received titles, the net effect, in terms of the weight of those titles, is closer to one for every two. In some LC main classes, however, we did much better than this, while in others we did much worse. Our students and faculty will have odds-on chances of finding reviewed titles in the history of theory and practice and special aspects of education (LC classes LA, LB, and LC); in English literature (PR); or in pediatrics (RJ). But they will have only about 1 chance in 10 of finding reviewed titles in Judaism and biblical studies (BM and $\mathrm{BS})$; in the history of Great Britain, France, Germany, Greece, and Italy (DA, DC, DD, DF, and DG); in European politics $(\mathrm{JN})$; in architecture and 


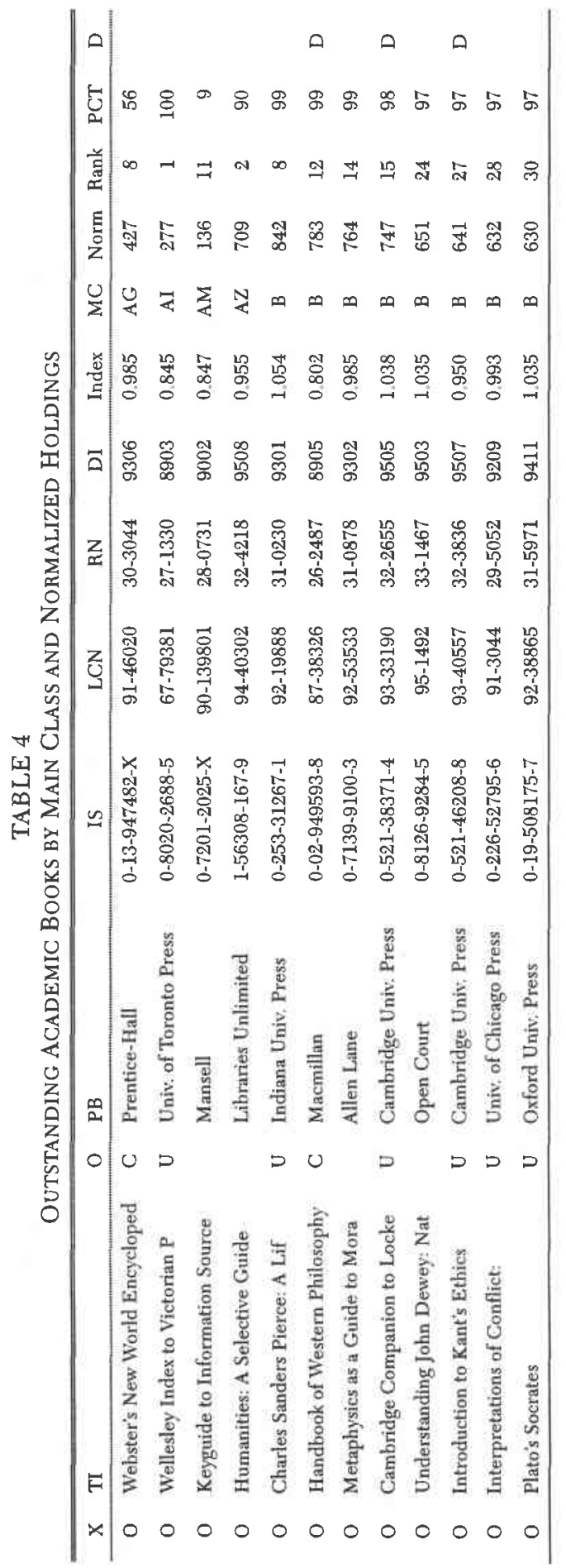




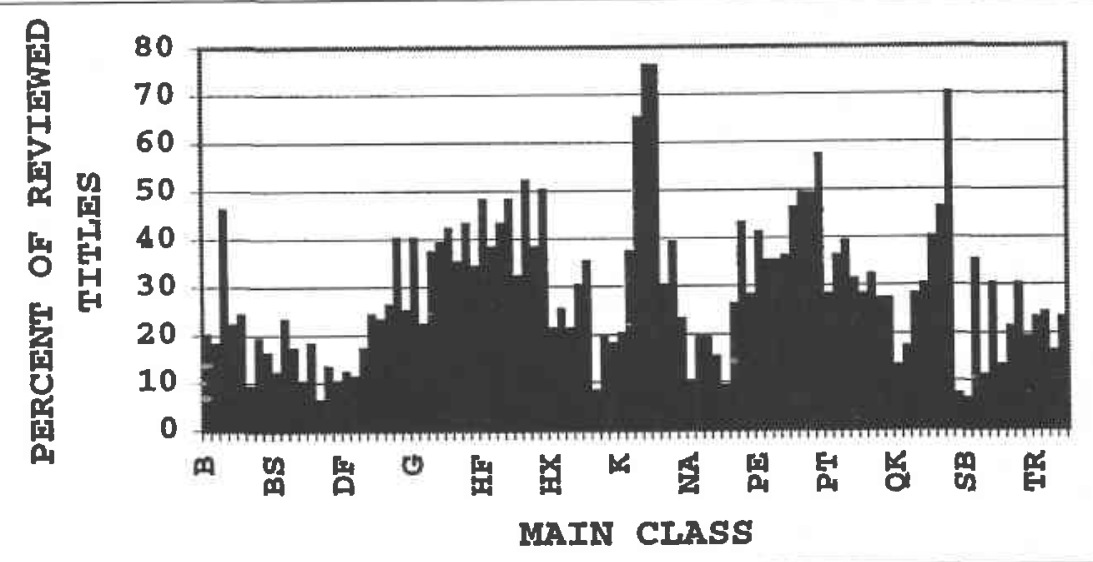

Figure 2. Percent of Reviewed Titles by Main Class.

decorative arts (NA and NK); in botany (QK); in agriculture and plant culture (S and SB); or in civil and mechanical engineering (TA and $\mathrm{TJ}$ ).

A possible explanation for the numbers in the last few main classes would almost certainly be that we always have been a general campus rather than a polytechnic one. But clearly there was no coordination in our previous acquisitions model, which, in attempting to control declining fortune with subjective allocations to book funds, allowed the backs and sides of a number of academic departments to go bare. Against an increasingly insistent counterpoint of regularly scheduled courses from those same departments-e.g., courses with titles like Comparative Religion and Understanding the Bible, the Emergence of Modern Europe and Twentieth-Century Europe, or Political Change in First and Third World Countries-we can only hope that our explanation will not sound to our accrediting agency too much like "O Fortuna" from Carmina Burana.

\section{Second Use of The Database: Cross-Disciplinary (Publisher) SEarching and ANaLYSIS}

Table 6 shows a second arrangement of the file that can be very helpful for collection development purposes. To permit this display, the publisher field was first normalized using authoritative forms from the WILSONDISC Cumulative Book Index; an asterisk indicates that the publisher form was not verified. Then the file was sorted on the normalized publisher field and subarranged on the International Standard Book Number field. We then took advantage of this new arrangement of the file by writing a short program that summarized the number of titles, normalized holdings, and percentiles for each publisher.

Table 7 shows summaries for the first 20 publishers; by using the SET FILTER command to establish a suitable threshold (in this case, PCT $>4,200$ ), we could create what are essentially cross-disciplinary subsets of the best-received presses and publishers from this summary file. Saunders (1996) found the differences between the circulation of university-press to commercial-publisher titles reviewed in Choice to be less than anticipated (5.091 to 6.404). And when we consider large-scale purchases and inclusions of the best-received presses and publishers reviewed in Choice from these cross-disciplinary summaries (that is, summaries in which the percentile expressions of rank are taken from many different main classes), we too found the differences to be less than anticipated. These cross-disciplinary summaries indicated that the average of the best-received universitypress titles reviewed in Choice (with a mean of 56 and a median of 57) was 
slightly better than the average of the best-received commercial-publisher titles reviewed in Choice (with a mean and a median of 53).

Table 8 shows a subset of the 54 bestreceived university presses, while Table 9 shows a subset of the 57 best-received commercial publishers from 1989 through 1995. During this seven-year period, these presses and publishers were responsible for two-thirds of the titles reviewed in Choice and three-fourths of the normalized holdings attached to these same titles in the OLUC. This list of presses and publishers was also responsible for three-fourths of the $\mathrm{OAB}$ during this seven-year period. And in fact, if we were to pursue the replication of publisher quality (Goedeken 1993) or of publisher reputation (Metz and Stemmer 1996) a step further by extending our seven-year file to include 1996 reviews, we would find an 80/20 core of 56 presses and 68 publishers among the $O A B$ much like the model for a publisher-based approval program (Calhoun, Bracken, and Firestein 1990) and very similar to this list. There seems to be enough of a correlation between quality and reception then to invite an application.

\section{An Academic Approval Program APPLICATION BASED ON THE Cross-Disciplinary (Publisher) ANalysis}

In earlier studies, authors have used frequently reviewed publishers or number of OAB items as collection assessment tool for individual academic collections (e.g., Stebelman 1996; Marquet and Diambra 1990), but in this part of our study we were interested instead in the reception of Choice Reviews for the general academic collection. As a consequence, we used the cross-disciplinary subsets of best-received presses and publishers as the basis of two notification-slip approval plans for core materials, both with dealers who had online systems accessible over the Intemet. Although we receive notification-slips each week from each of these vendors, we also can capture the bibliographic data from the slips through a pro- gram developed by local system personnel that draws the data down over the Internet into a relational database file.

Table 10 displays the bibliographic data from the top of this file as it appeared at the end of the 1996 calendar year. Again, most of the fields are identified with two- and three-letter mnemonics that are recognizable from Choice Reviews. The titles in the display are sorted by main class and subarranged in descending order by OLUC holdings; but in this example, because the titles were searched in weekly batches one month after having been profiled by the vendor, the holdings have not been normalized. This process of cumulating a large file of notification-slip titles, each of which was searched one month after having been profiled, allowed us to create consistent monthly subsets by using filters and to print these monthly lists with the rank and percentile expression of rank from the larger file still attached.

Table 11 is an example of such a monthly list. This list can be used by subject bibliographers as a guide to two notification-slip referral files, in which the bibliographers can find additional bibliographic information, such as the academic affiliation of the author, or a complete list of subject added entries. The overview that the monthly list and the coordinated referral files provide allows a combination of cross-disciplinary selection from a single issue, characteristic of a cooperative project (Erickson 1992); at the same time, it allows discipline-oriented selection over a period of time equivalent to several issues, characteristic of a retrospective project (Childress and Gibbs 1989).

This combination of discipline-oriented and cross-disciplinary searching, which is an attribute of the larger file, is something we would want to preserve in an online version of the monthly list once we were able to support a local area network that linked the subject bibliographers' computers and provide access to the online referral files in our vendors' systems over the Internet. If we were able to maintain the perspective of such a monthly list, say, at a Web site, while at the same time furnishing access to the online 


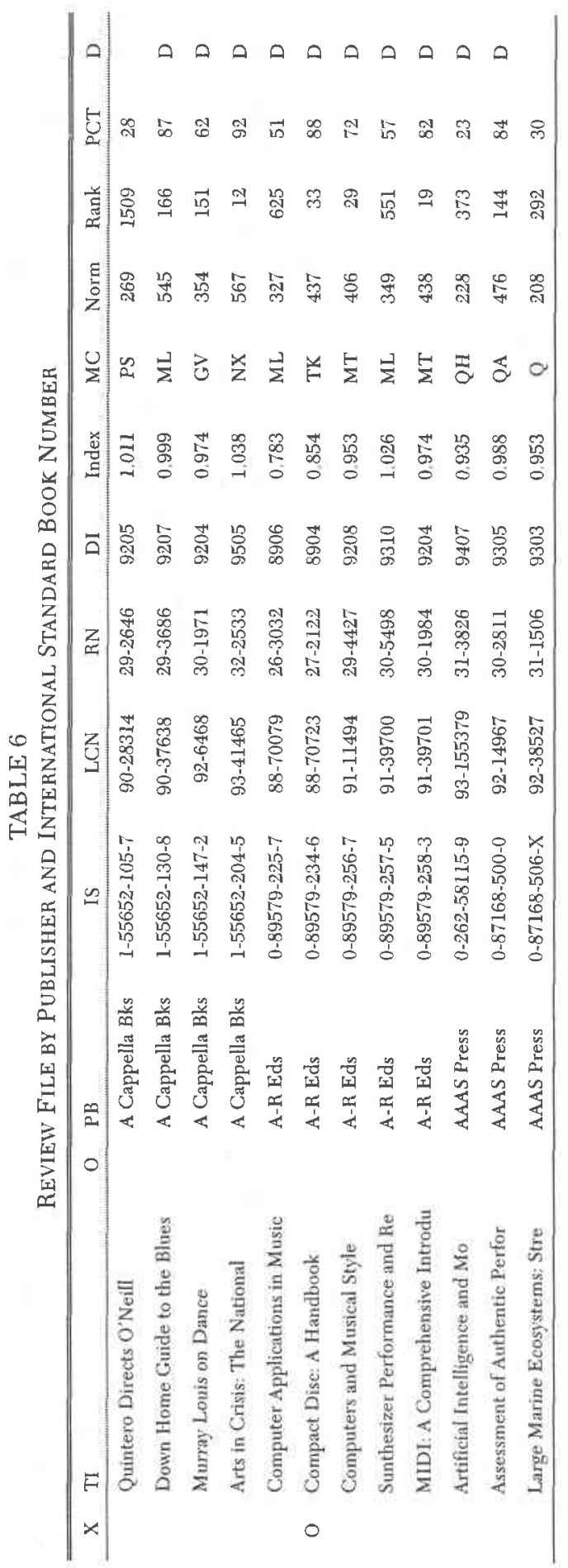


TABLE 7

Summary File of Publishers and Normalized Holdings

\begin{tabular}{|c|c|c|c|c|c|}
\hline $\mathrm{O}$ & $\mathrm{PB}$ & $\mathrm{TT}$ & NORM & PCT & AVE \\
\hline & A Cappella Bks. & 4 & 1,735 & 269 & 67 \\
\hline & A-R Eds & 5 & 1,957 & 350 & 70 \\
\hline & AAAI Press & 1 & 228 & 23 & 23 \\
\hline & AAAS Press & 5 & 1,486 & 210 & 42 \\
\hline & AArhus Univ. Press & 1 & 28 & 0 & 0 \\
\hline & Abacus Press & 1 & 87 & 8 & 8 \\
\hline & Abaris Bks. & 2 & 640 & 92 & 46 \\
\hline C & Abbeville Press & 68 & 31,214 & 4,861 & 71 \\
\hline \multirow[t]{4}{*}{$\mathrm{C}$} & ABC-CLIO & 97 & 60,541 & 7,444 & 77 \\
\hline & $\mathrm{ABCS}$ & 1 & 10 & 2 & 2 \\
\hline & Abdelmalek Essadi Univ. King & 1 & 31 & 4 & 4 \\
\hline & Abhinav Publs. & 7 & 594 & 34 & 5 \\
\hline
\end{tabular}

referral files over the Internet, we would have a prototype for a systemwide project-something that heretofore has been limited to the more stringent geographical proximity characteristic of traditional cooperative projects (Erickson 1992).

Our experience thus far has shown that the one-month holdings from the notification-slip file form a 70/30 core (that is, $70 \%$ of the holdings appear on $30 \%$ of the titles), just as the normalized holdings in the Choice Reviews file form a 60/40 core (that is, $60 \%$ of the normalized holdings appear on $40 \%$ of the titles). This would seem to support MacLam's (1992) charac- terization of Choice's selection procedures, in which inappropriate material and recognizably bad books are weeded out and a more consistent file is produced. We started our notification-slip approval plans in October 1995, by the end of the 1996 calendar year, we found that the list of 54 university presses had produced 5,261 notification slips, while the list of 57 commercial publishers produced 10,027 slips. Also by the end of the calendar year, we found that the university-press list had predicted 2,714 Choice reviews, while the commercialpublisher list predicted 1,856.

The lists accurately predicted two-

Commerical core
University core

other
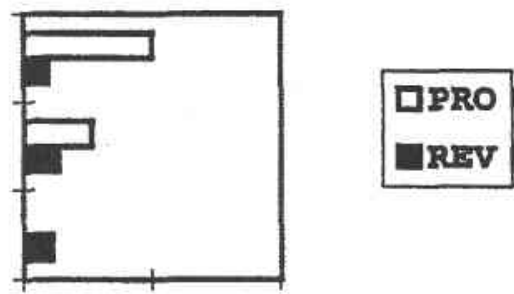

o 1000020000

Figure 3. Reviewed Titles within Profiled Titles. 
TABLE 8

Core University Press and Normalized Holdings

\begin{tabular}{|c|c|c|c|c|c|}
\hline $\mathrm{O}$ & $\mathrm{PB}$ & $\mathrm{TI}$ & NORM & PCT & AVE \\
\hline $\mathrm{U}$ & Brookings Institution & 106 & 68,903 & 9,380 & 88 \\
\hline U & Cambridge Univ. Press & 2,140 & 702,050 & 116,206 & 54 \\
\hline $\mathrm{U}$ & Columbia Univ. Press & 314 & 128,786 & 19,933 & 63 \\
\hline $\mathrm{U}$ & Cornell Univ. Press & 539 & 172,253 & 28,585 & 53 \\
\hline $\mathrm{U}$ & Duke Univ. Press & 216 & 70,113 & 11,402 & 53 \\
\hline $\mathrm{U}$ & Fairleigh Dickinson Univ. Press & 143 & 36,132 & 5,389 & 38 \\
\hline U & Harvard Univ. Press & 483 & 233,752 & 34,854 & 72 \\
\hline $\mathrm{U}$ & Indiana Univ. Press & 467 & 176,096 & 28,196 & 60 \\
\hline $\mathrm{U}$ & Johns Hopkins Univ. Press & 426 & 157,298 & 25,663 & 60 \\
\hline U & Louisiana State Univ. Press & 184 & 71,891 & 10,238 & 56 \\
\hline $\mathbf{U}$ & Manchester Univ. Press & 221 & 44,267 & 5,901 & 27 \\
\hline $\mathrm{U}$ & MIT Press & 386 & 145,491 & 24,653 & 64 \\
\hline U & National Acad. Press & 120 & 50,074 & 7,908 & 66 \\
\hline $\mathbf{U}$ & New York Univ. Press & 216 & 69,651 & 10,360 & 48 \\
\hline $\mathbf{U}$ & Oxford Univ. Press & 2,434 & 920,550 & 135,505 & 56 \\
\hline $\mathrm{U}$ & Pennsylvania State Univ. Press & 207 & 62,313 & 9,889 & 48 \\
\hline $\mathrm{U}$ & Princeton Univ. Press & 800 & 298,744 & 49,422 & 62 \\
\hline $\mathrm{U}$ & Rutgers Univ. Press & 246 & 102,684 & 15,436 & 63 \\
\hline $\mathrm{U}$ & Smithsonian Institution Press & 212 & 85,590 & 12,882 & 61 \\
\hline $\mathrm{U}$ & Southern Illinois Univ. Press & 139 & 43,931 & 6,847 & 49 \\
\hline $\mathrm{U}$ & Stanford Univ. Press & 321 & 100,231 & 16,766 & 52 \\
\hline $\mathrm{U}$ & State Univ of New York Press & 547 & 167,959 & 26,342 & 48 \\
\hline U & Syracuse Univ. Press & 82 & 31,620 & 5,064 & 62 \\
\hline U & Teachers College Press & 83 & 40,443 & 5,398 & 65 \\
\hline $\mathrm{U}$ & Temple Univ Press & 215 & 80,034 & 12,538 & 58 \\
\hline U & University of Alabama Press & 106 & 32,167 & 4,610 & 43 \\
\hline $\mathrm{U}$ & University of Arizona Press & 129 & 42,094 & 6,504 & 50 \\
\hline $\mathrm{U}$ & University of California Press & 803 & 285,044 & 45,851 & 57 \\
\hline $\mathrm{U}$ & University of Chicago Press & 539 & 227,211 & 35,462 & 66 \\
\hline $\mathrm{U}$ & University of Delaware Press & 103 & 29,354 & 4,569 & 44 \\
\hline $\mathrm{U}$ & University of Georgia Press & 214 & 74,364 & 10,931 & 51 \\
\hline $\mathrm{U}$ & University of Hawaii Press & 86 & 22,606 & 4,057 & 47 \\
\hline $\mathrm{U}$ & University of Illinois Press & 333 & 119,784 & 17,813 & 53 \\
\hline $\mathrm{U}$ & $\begin{array}{l}\text { University of Massachusetts } \\
\text { Press }\end{array}$ & 124 & 50,038 & 7,420 & 60 \\
\hline $\mathbf{U}$ & University of Michigan Press & 238 & 71,575 & 11,363 & 48 \\
\hline $\mathrm{U}$ & University of Minnesota Press & 111 & 34,267 & 5,568 & 50 \\
\hline $\mathrm{U}$ & University of Missouri Press & 124 & 43,613 & 6,632 & 53 \\
\hline
\end{tabular}


TABLE 8

Core University Press and Normalized Holdings, continued

\begin{tabular}{llrrrc}
\hline \hline & & & & \\
O & PB & TI & NORM & PCT & AVE \\
\hline U & University of North Carolina Press & 315 & 130,704 & 19,907 & 63 \\
U & University of New Mexico Press & 123 & 37,417 & 5,691 & 46 \\
U & University of Nebraska Press & 184 & 62,766 & 9,163 & 50 \\
U & University of Oklahoma Press & 166 & 64,600 & 9,029 & 54 \\
U & University of Pennsylvania Press & 182 & 58,332 & 9,683 & 53 \\
U & University of Pittsburgh Press & 121 & 37,247 & 5,692 & 47 \\
U & University of South Carolina Press & 150 & 48,781 & 7,806 & 52 \\
U & University of Tennessee Press & 113 & 42,402 & 6,570 & 58 \\
U & University of Texas Press & 205 & 70,450 & 11,772 & 57 \\
U & University of Toronto Press & 250 & 54,707 & 7,412 & 30 \\
U & University of Washington Press & 100 & 30,457 & 4,502 & 45 \\
U & University of Wisconsin Press & 142 & 52,483 & 7,964 & 56 \\
U & University Press of Kansas & 143 & 64,589 & 9,334 & 65 \\
U & University Press of Kentucky & 138 & 49,593 & 7,694 & 56 \\
U & University Press of Virginia & 110 & 38,868 & 6,167 & 56 \\
U & Wayne State Univ. Press & 101 & 29,421 & 4,760 & 47 \\
U & Yale Univ. Press & 699 & 320,817 & 49,736 & 71 \\
\hline
\end{tabular}

thirds of the 1996 Choice reviews and three-fourths of the $1996 \mathrm{OAB}$ items. As figure 3 will make clear, we were anticipating that approximately one of every four commerical publisher titles and one of every two university press titles profiled would be reviewed. What we were not anticipating, however, was the extent to which the restriction on date (the review having to appear within six months of publication, which MacLam had described) would affect our operation. We found that the amount of time between a title's having been profiled by one of our vendors and the book's being reviewed by Choice had a mean of 151 days and a median of 152 days. As a result, our performance for the first five dates of issue in 1996 looked like a long upward slope. By the end of the year, using the standard numbers from the IS and LCN fields, we were able to find only 3,277 approval titles among 6,730 review titles (49\%). Our performance for the last six dates of issue in 1996, however, looks more like level high ground. During that time, we were able to find 2,219 ap- proval titles among 3,722 review titles $(60 \%)$-including $208 \mathrm{OAB}$ approvals out of $311 \mathrm{OAB}$ reviews $(67 \%)$.

\section{CORRELATION OF EARLY SEARCHES FROM THE APPROVAL FILE WITH LATER SEARCHES FROM THE REVIEW FILE}

One last illustration will help to make clear how the one-month holdings from the approval file can be related to the normalized holdings from the review file through the 3,277 titles that we have been able to match. In the course of our third project, we searched the 1996 titles in April 1997; the effect of this early searching can be seen in the shelving off of the average holdings in the 1996 dates of issue at the far right of the display in figure 3. The results for January 1997 (which include the 1996 OAB list), as well as the results for the last six dates of issue in the display (June 1996 through December 1996), are obviously less complete than the data for the normalized holdings would be following our fourth searching 
TABLE 9

Core Commercial Publishers and Normalized Holdings

\begin{tabular}{|c|c|c|c|c|c|}
\hline 0 & PB & TI & NORM & PCT & AVE \\
\hline $\mathrm{C}$ & Abbeville Press & 68 & 31,214 & 4,861 & 71 \\
\hline C & ABC-CLIO & 97 & 60,541 & 7,444 & 77 \\
\hline C & Abrams & 215 & 96,328 & 14,994 & 70 \\
\hline $\mathrm{C}$ & Academic Press & 166 & 54,209 & 9,202 & 55 \\
\hline C & Addison-Wesley & 83 & 40,532 & 5,549 & 67 \\
\hline C & Basic Bks. & 191 & 154,283 & 17,026 & 89 \\
\hline C & Beacon Press & 73 & 42,834 & 5,707 & 78 \\
\hline C & Blackwell & 459 & 135,462 & 21,300 & 46 \\
\hline C & Chapman \& Hall & 133 & 29,385 & 5,102 & 38 \\
\hline C & Continuum & 87 & 37,896 & 5,487 & 63 \\
\hline $\mathrm{C}$ & Erlbaum & 181 & 61,473 & 8,746 & 48 \\
\hline $\mathrm{C}$ & Facts On File & 258 & 151,940 & 19,984 & 77 \\
\hline $\mathrm{C}$ & Free Press & 170 & 126,030 & 14,918 & 88 \\
\hline C & Gale Res. & 226 & 115,651 & 15,412 & 68 \\
\hline C & Garland & 585 & 162,838 & 20,044 & 34 \\
\hline C & Greenwood Press & 1,295 & 353,501 & 48,269 & 37 \\
\hline $\mathrm{C}$ & Guilford Press & 97 & 43,083 & 6,155 & 63 \\
\hline C & Hall, G.K. \& Co. & 179 & 66,205 & 8,860 & 49 \\
\hline C & Harper \& Row & 89 & 61,580 & 7,303 & 82 \\
\hline C & Harpercollins Pubs & 60 & 44,225 & 5,172 & 86 \\
\hline C & Houghton Mifflin & 84 & 76,232 & 7,356 & 88 \\
\hline $\mathrm{C}$ & Island Press (Covelo) & 82 & 43,657 & 6,165 & 75 \\
\hline $\mathrm{C}$ & Jossey-Bass & 182 & 105,707 & 13,839 & 76 \\
\hline C & Knopf & 148 & 132,461 & 13,306 & 90 \\
\hline $\mathrm{C}$ & Lexington Bks. & 92 & 41,427 & 5,935 & 65 \\
\hline C & Little, Brown & 61 & 53,220 & 5,203 & 85 \\
\hline $\mathrm{C}$ & Macmillan & 123 & 82,933 & 9,937 & 81 \\
\hline $\mathrm{C}$ & Mcfarland \& Co. & 263 & 75,609 & 10,601 & 40 \\
\hline C & McGraw-Hill & 257 & 85,817 & 15,259 & 59 \\
\hline$C$ & Morrow & 112 & 87,213 & 9,603 & 86 \\
\hline $\mathrm{C}$ & Norton & 298 & 200,933 & 23,775 & 80 \\
\hline C & Pantheon Bks. & 48 & 35,167 & 4,222 & 88 \\
\hline $\mathrm{C}$ & Paragon House & 87 & 35,347 & 5,302 & 61 \\
\hline $\mathrm{C}$ & Plenum Press & 130 & 51,605 & 7,483 & 58 \\
\hline $\mathrm{C}$ & Praeger Pubs. & 755 & 219,342 & 31,953 & 42 \\
\hline C & Prentice-Hall & 201 & 48,945 & 8,406 & 42 \\
\hline $\mathrm{C}$ & Quorum Bks. & 167 & 56,177 & 8,482 & 51 \\
\hline $\mathrm{C}$ & Random House & 131 & 122,275 & 11,744 & 90 \\
\hline $\mathrm{C}$ & Rienner Pubs. & 146 & 38,866 & 7,213 & 49 \\
\hline C & Rizzoli Int. Publs. & 129 & 40,837 & 6,777 & 53 \\
\hline C & Routledge & 1,025 & 267,003 & 38,300 & 37 \\
\hline $\mathrm{C}$ & Sage Publs. & 342 & 126,668 & 18,785 & 55 \\
\hline $\mathrm{C}$ & Scareciow Press & 274 & 72,659 & 10,862 & 40 \\
\hline C & Schirmer Bks. & 50 & 26,718 & 4,063 & 81 \\
\hline $\mathrm{C}$ & Scribner & 116 & 90,357 & 10,117 & 87 \\
\hline C & Sharpe M.E. & 167 & 48,979 & 8,185 & 49 \\
\hline C & Simon \& Schuster & 103 & 74,803 & 8,405 & 82 \\
\hline $\mathrm{C}$ & Springer-Verlag & 365 & 89,259 & 14,635 & 40 \\
\hline C & St. Martin's Press & 1,007 & 232,437 & 31,726 & 32 \\
\hline $\mathrm{C}$ & Thames \& Hudson & 104 & 37,019 & 5,990 & 58 \\
\hline C & Times Bks. & 62 & 54,110 & 5,593 & 90 \\
\hline C & Transaction Bks, & 166 & 46,473 & 6,845 & 41 \\
\hline C & Twayne Pubs. & 363 & 196,829 & 29,304 & 81 \\
\hline C & Van Nostrand Reinhold & 117 & 37,373 & 6,427 & 55 \\
\hline C & Viking & 91 & 65,845 & 7,806 & 86 \\
\hline C & Westview Press & 634 & 195,535 & 32,081 & 51 \\
\hline $\mathrm{C}$ & Wiley & 539 & 161.791 & 27.460 & 51 \\
\hline
\end{tabular}




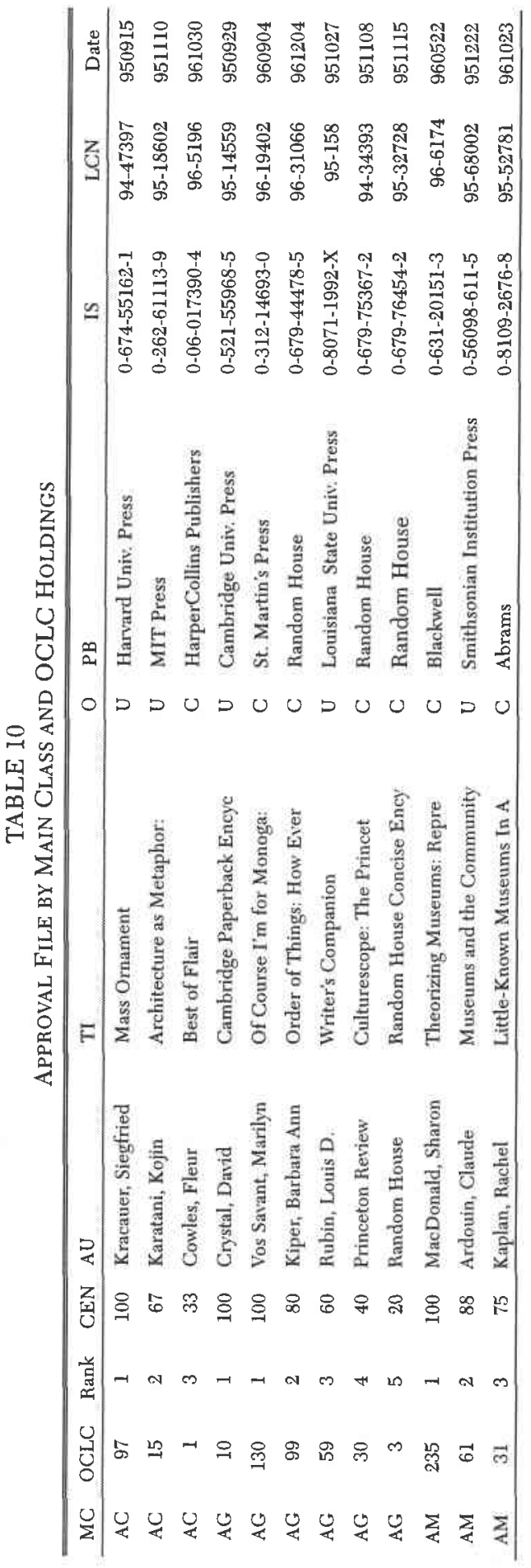




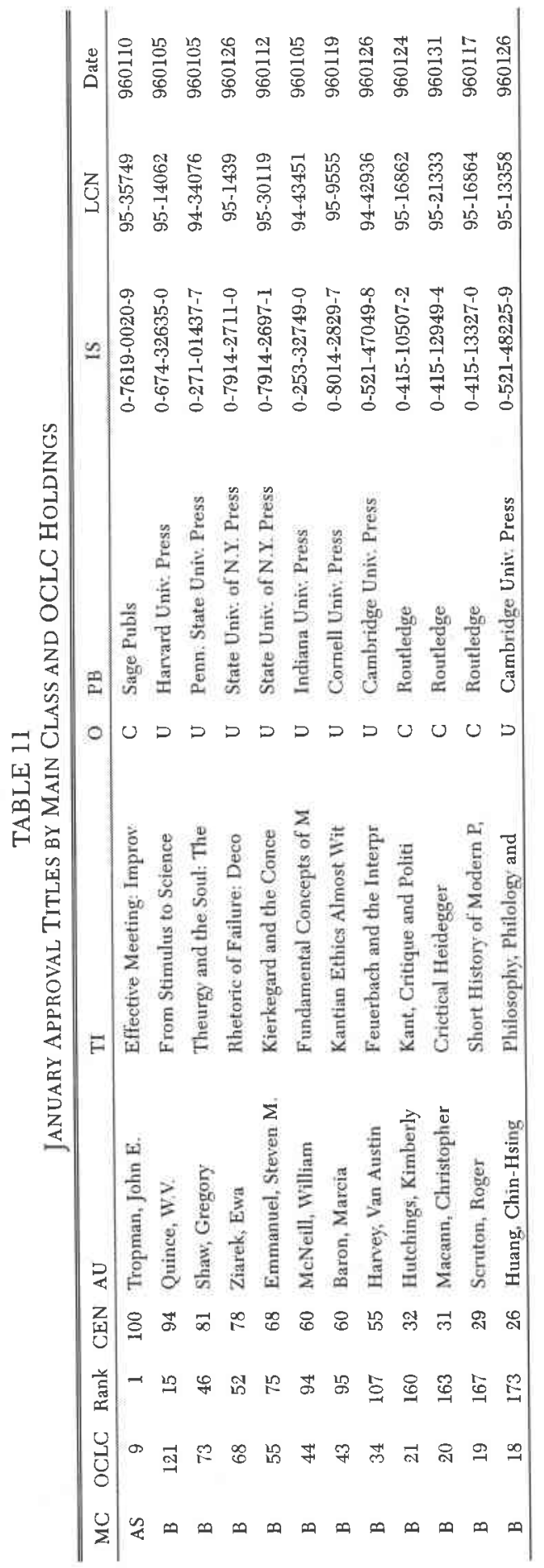




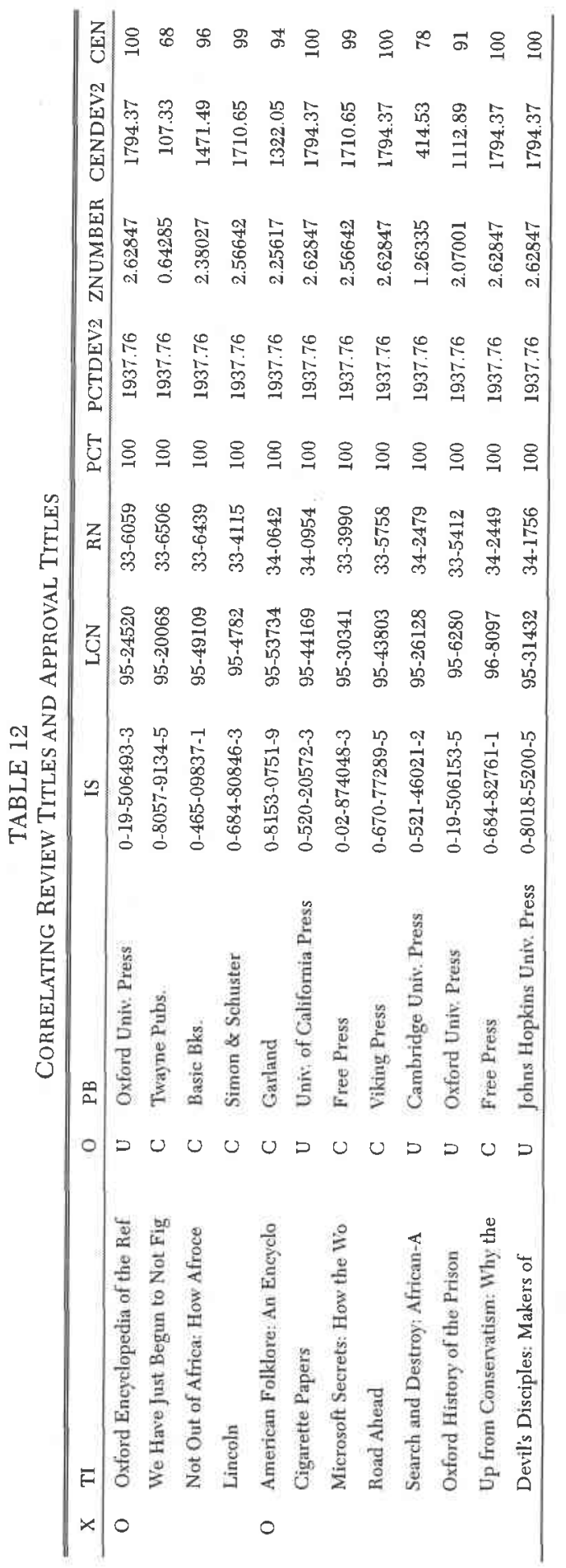


project. Nevertheless, we can assign an index to each of the 1996 dates of issue that will permit us to normalize the holdings of the 3,277 titles in question. And with the caveat in mind-that the 1996 normalized holdings will not have the same sense of closure that the succeeding year's OAB list would provide (the 1997 OAB list)-we will proceed.

Table 12 shows the Pearson productmoment correlation between the percentile expression of rank for the normalized holdings of 3,277 titles from the review file to the percentile expression of rank for the one-month holdings for the same tithes from the approval file. We have called the latter "centile" (CEN), in order to distinguish it from the former. First, the review file and the approval file were indexed on common key expressions (the IS and LCN fields). Using the relational features of the software, we linked the review file to the approval file according to those common key expressions. And the data for the centile expression of rank from the one-month searches in the approval file were used to replace the CEN field in the review file. Then, the means for both PCT and CEN were found (55.98 and 57.64 , respectively). Next, the standard deviations for the two (26.12 and 27.16) were found. And finally, the product-moment correlation coefficient (.4678) was calculated.

The 3,277 records common to the approval and review files had a CEN mean of 58 and median of 60 . This is in keeping with what the $70 / 30$ core from the approval file and the 60/40 core from the review file had already suggested. This offers further support to MacLam's (1992) characterization of Choice's selection procedures, which weed out inappropriate material and recognizably bad books: from as early as one month, reviewed titles enjoy better than average reception. Also because these 3,277 records have a code $(O)$ to identify $O A B$ items in the review file, we can create subsets of $O A B$ and non- $O A B$ records. When we did this, we found that the mean and median for the $\mathrm{OAB}$ records from the PCT field was 69 and 73 ; and the mean and median for the non-OAB records, 55 and 54 . It might be that a large number of librarians ordered these titles from the 1996 OAB list (which appeared in January 1997) and were able to receive and catalog them in time for the OLUC holdings to appear among the data from the addendum to our third searching project (which occurred in April 1997). But it seems more likely that the 1996 normalized holdings reflect some innate quality already inherent in the titles that the reviewers and editors highlighted with the list. Even the very earliest resultsthe one-month holdings from the approval file-reflect something of this. The mean and median for the OAB records from the CEN field were 61 and 63 , and the mean and median for the non-OAB records were 57 and 60 .

\section{The SIgnificance OF 70/30}

\section{Approval Core and 60/40 Review CORE: TIMELY ACQUISITIONS OF NEXT YeAR's OUTSTANDING ACADEMIC BOOKS}

We were able to correlate the normalized holdings of the review file with the onemonth holdings of the approval file, and we are willing to speculate, on the basis of that correlation, that there is a conceptual equivalence between the $60 / 40$ core of the review file with the 70/30 core of the approval file worth further investigation. The advantage in establishing a correlation between the review file and the approval file and suggesting a link between the 60/40 core and the $70 / 30$ core (as Budd (1991) has suggested already), is that of utility. The earlier we recognize core materials, the better our chances will be of finding those materials available. Choice Reviews appears several years ahead of the next edition of Books for College Libraries, and notification slips from vendor profiles appear several months ahead of Choice Reviews. If we are willing to search the reviews in the OLUC once the OAB list from the succeeding year has appeared, we can predict from the 60/40 core what Books for College Libraries, 4 th ed. will contain. And if we search the notification slips in the 
OLUC one month after they have been profiled, we can add a depth to the bibliographic data that only a 200 -word review several months later will rival. We believe the succeeding-year search (like a year'send political analysis) and the one-month search (like a first-hour election poll) are well worth the effort to get an accurate forecast of what the best-received materials will nost likely be.

\section{WORKS CITED}

Balay, Robert. 1988. Brave new Choice. Choice 26: 55-57.

Budd, John M. 1991. The utility of a recommended core list: An examination of Books for college libraries, $3 \mathrm{~d}$ ed. Journal of academic librarianship 17: 140-44.

Calhoun, John C., James K. Bracken, and Kenneth L. Firestein. 1990. Modeling an academic approval plan. Library resources \& technical services 34: 367-79.

Carlo, Paula Wheeler, and Allen Natowitz. 1995. Choice book reviews in American history, geography, and area studies: An analysis for 1988-1993. Library acquisitions: Practice of theory 19: 153-65.

Childress, Boyd, and Nancy Gibbs. 1989. Collection assessment and development using B/NA approval plan referral slips. Collection management 11: 137-43.

Erickson, Rodney. 1992. Choice for cooperative collection development. Library acquisitions: Practice \& theory 16: 43-49.

Goedeken, Edward A. 1993. An index of publisher quality revisited: A partial replica- tion. Library acquisitions: Practice \& theory 17: 263-68.

Graf, Francine. 1995. Reviewer recruitment: An overview. Choice 32: 892.

Greene, Robert J., and Charles D. Spornick. 1995. Favorable and unfavorable book reviews: A quantitative study. Journal of academic librarianship 21: 449-53.

Leavy, Marvin D. 1992. An exploration of the validity of Choice's "Outstanding Acadernic Books." Journal of academic librarianship 18: 83-86.

MacLam, Helen. 1992. About Choice. Collection management 16: 73-79.

Marquart, Steve, and Eileen Diambra. 1990. Quality declines with quantity: Comparing annual acquisitions to the Choice "Outstanding Academic Books" list. In Acquisitions '90: Conference on acquisitions, budgets, and collections, ed. David C. Genaway, 279-84. Canfield, Ohio: Genaway \& Assocs.

Metz, Paul, and John Stemmer. 1996. A reputational study of academic publishers. College \& research libraries 57: 234-47.

Sabosik, Patricia E. 1992. Review coverage. Choice 29: 690 .

Saunders, E. Stewart. 1996. Library circulation of university press publications. Journal of scholarly publishing 27: 166-70.

Serebnick, Judith. 1992. Selection and holdings of small publishers' books in OCLC libraries: A study of the influence of reviews, publishers, and vendors. Library quarterly 62: 259-94.

Stebelman, Scott. 1996. Using Choice as a collection assessment tool. Collection building 15, no. 2: 4-11. 


\section{LOOKING FOR A}

\section{CATAlOging PARTNer?}

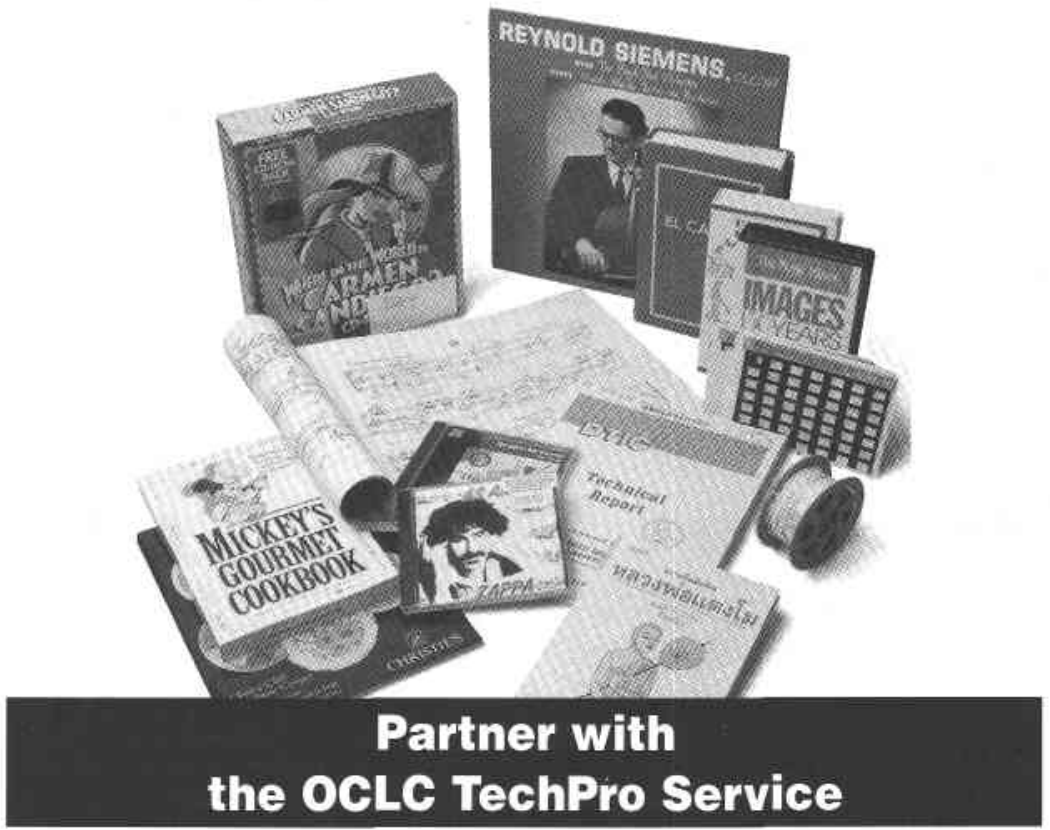

Since 1985, the OCLC TechPro service has helped hundreds of libraries eliminate their cataloging backlogs and keep pace with ongoing cataloging, giving patrons prompt access to materials.

TechPro offers:

- Customized cataloging and physical processing to match your exact specifications

- Cataloging of materials in all bibliographic formats and in many languages

- Quality cataloging at prices that can reduce your overall cataloging costs

Consider the TechPro Basic Price Option if you need cataloging for recently published books, serials or videos, but don't need complex editing or extensive local data added to records. For straightforward projects, this simplified approach to contract cataloging may be just what you need.

Looking for a partner to keep your cataloging up-to-date? Contact the OCLC TechPro service today.

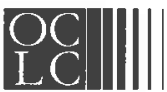

